ช

OPEN ACCESS

EDITORES

- Miguel Oliveira, Jr. (UFAL)

- René Almeida (UFS)

AVALIADORES

- Elisângela Silva (UESB)

- Lucas Silva (UFAL)

DATAS

- Recebido: 09/08/2021

- Aceito: 07/09/2021

- Publicado: 30/09/2021

COMO CITAR

BORGES, Humberto (2021). Variação e mudança linguística na perspectiva da Gramática Gerativa. Cadernos de Linguística, v. 2, n. 4, e470.
ENSAIO TEÓRICO

\section{VARIAÇÃO E MUDANÇA LINGUÍSTICA NA PERSPECTIVA DA GRAMÁTICA GERATIVA}

\author{
Humberto BORGES (D) $\boldsymbol{\Delta}$ \\ Universidade Federal de Jataí (UFJ)
}

RESUMO

Este artigo discute dois processos comuns às línguas naturais, quais sejam, variação e mudança, a partir da perspectiva da linguística gerativa, que concebe a capacidade da espécie humana de adquirir línguas como uma dotação genética. Mais especificamente, este artigo oferece uma reflexão sobre os pressupostos teóricos envolvidos nos conceitos de variação e mudança, apresentando o tratamento e o desenvolvimento desses conceitos e conceitos paralelos em duas etapas da Gramática Gerativa: a teoria dos Princípios e Parâmetros e o Programa Minimalista. Contra modelos teóricos que defendem a possibilidade de transmissão linguística irregular e certa gradualidade no processo de mudança sintática, os argumentos deste trabalho estão muito mais em consonância com uma visão de descontinuidade para o processo de mudança sintática do que aqueles que concebem uma aquisição imperfeita da linguagem para explicar a mudança sintática.

\section{ABSTRACT}

This article discusses two processes common to natural languages, namely, variation and change, from generative linguistic framework, which conceives the capacity of the human species to acquire languages as a genetic endowment. More specifically, this article provides an analysis of the theoretical assumptions involved in the concepts of variation and change, presenting the treatment and development of these concepts and parallel concepts in two stages of generative frameworks: the Principles \& Parameters theory and the Minimalist 
Program. Against theoretical models that defend the possibility of irregular linguistic transmission and a certain gradualness in the process of syntactic change, the arguments of this work are much more completely in harmony with a view of discontinuity for the process of syntactic change than those which conceive an imperfect language acquisition for explaining syntactic change.

PALAVRAS-CHAVE

Variação Linguística; Mudança Sintática; Gramática Gerativa.

KEYWORDS

Language Variation; Syntactic Change; Generative Grammar. 


\section{INTRODUÇÃO'}

Na linguística gerativa, cada língua é vista como um procedimento gerativo que produz um conjunto infinito de representações estruturadas hierarquicamente e com interpretações sistemáticas em interfaces com dois sistemas de desempenho, o sistema articulatórioperceptual e o sistema conceitual-intencional (cf. BERWICK; CHOMSKY, 2016). Uma língua compreendida nesses termos é chamada de língua-I. A teoria de uma língua-I é o estudo de sua gramática gerativa, e a teoria geral das línguas-I constitui o estudo da Gramática Universal (GU). A GU é a teoria do componente genético da faculdade da linguagem, um órgão modular da mente/cérebro humano que possibilita a aquisição e o uso de língua(s). Crucialmente, os estudos sobre a GU buscam determinar o que é fixo na propriedade básica das línguas naturais e definir as opções de variação. Essa abordagem biolinguística das línguas naturais está ligada a três fatores que, segundo Chomsky (2005), interagem para determinar o design das línguas-l:

(1) $1^{\circ}$ fator: a dotação genética, aparentemente uniforme na espécie humana, o tópico da GU. A carga genética interpreta parte do ambiente como experiência linguística e determina o percurso do desenvolvimento da faculdade de linguagem em direção às línguas-I. A interpretação do ambiente como experiência linguística constitui tarefa singular que a criança desempenha de modo reflexivo;

$2^{\circ}$ fator: a experiência, que leva à variação, i.e., os dados linguísticos primários (do inglês, Primary Linguistic Data). Os dados linguísticos primários permitem a aquisição de língua e conduzem a variação dentro de um escopo bastante estreito;

$3^{\circ}$ fator: princípios de arquitetura estrutural e de restrições sem domínio específico, isto é, princípios independentes da linguagem ou até mesmo do organismo. Dissociada de outras habilidades e capacidades cognitivas, a aquisição de uma língua-I baseia-se em restrições da GU e em princípios independentes da linguagem.

$\mathrm{O} 2^{\circ}$ Fator indica que a variação é uma propriedade inerente às línguas naturais. Ora, é fato que as línguas diferem umas das outras em seus vários aspectos constitutivos: no vocabulário (léxico); na estrutura dos sons (fonologia); na estrutura das palavras (morfologia); na estrutura de frases (sintaxe); nos aspectos semânticos (semântica) e pragmáticos (pragmática). Definir a extensão e os limites da variação é, contudo, um desafio para os estudos linguísticos. Na linguística gerativa, com o objetivo de compreender

1 O presente artigo resulta de um dos capítulos da tese de doutorado do autor. 
a variação tal como ela é manifesta na estrutura formal das línguas naturais, são estudadas as maneiras pelas quais a diversidade linguística é codificada no sistema computacional cognitivo que gera estruturas linguísticas, ou seja, que gera gramáticas. Nessa perspectiva, o pesquisador lida com o ponto em que a diversidade linguística é restringida pela GU subjacente às línguas humanas e busca responder quais são as diferentes dimensões que permitem a diversidade linguística. Outra característica inerente às línguas humanas é o fato de que elas são dinâmicas, isto é, elas mudam no decorrer do tempo; e isso ocorre apesar de todo tipo de empreendimento sócio-político e educacional para impedir que elas mudem. Por conta dessa dinamicidade, as propriedades linguísticas de uma dada língua são historicamente instáveis.

Para a Teoria da Variação e Mudança Linguística (WEINREICH; LABOV; HERZOG, 1968), a mudança linguística no eixo diacrônico é, possivelmente, um dos fenômenos mais complexos que existe para se estudar, pois é difícil precisar uma razão aparente que a explique em um dado período numa determinada língua, especialmente quando não há influência externa. Em outras palavras, nessa perspectiva, ao lidar com a mudança linguística, é extremamente difícil determinar o que a causou em um dado estágio da língua. Weinreich, Labov e Herzog (1968) traduziram esse impasse como o problema da implementação:

\footnotetext{
Quais fatores podem explicar a implementação das mudanças? Por que as mudanças em um traço estrutural ocorrem em uma dada língua particular em um dado momento, mas não em outras línguas com o mesmo traço, ou na mesma língua em outros momentos? (WEINREICH; LABOV; HERZOG, 1968, p. 102, traduzido). ${ }^{2}$
}

O problema da implementação impõe outras questões cujas respostas, visíveis apenas no eixo diacrônico da língua, são difíceis de decifrar: por qual razão determinada mudança é desencadeada em uma língua em particular em um dado momento histórico? Uma vez iniciado, por que o processo de mudança continua a atuar? Diante do problema da implementação, o pesquisador deve lançar mão de duas hipóteses razoáveis para lidar com casos de mudança gramatical, quais sejam: primeiramente, pressupõe-se que a mudança é espontânea, ou seja, interna/endógena, aquela que ocorre quando algo na gramática de uma dada língua muda sem que haja alguma causa externa aparente. De outro modo, argumenta-se que a mudança é induzida por contato linguístico, ou seja, é causada pela transferência de um traço linguístico de uma língua para outra numa dada situação de contato entre línguas. Nesse caso, entretanto, não é fácil determinar se, de fato, a mudança em uma dada língua $A$ foi provocada por influência de uma dada língua

2 No original: The Actuation Problem: "What factors can account for the actuation of changes? Why do changes in a structural feature take place in a particular language at a particular time, but not in other languages with the same feature, or in the same language at other times? (WEINREICH; LABOV; HERZOG, 1968, p. 102). 
B. Apesar de ontologicamente distintos, em ambos os fenômenos - mudança interna ou mudança induzida por contato linguístico -, o pesquisador precisa examinar dois estágios distintos da língua: o primeiro é anterior à mudança; e o segundo retrata a língua após a mudança.

Fuß (2016) argumenta que uma resposta ao problema da implementação na perspectiva da Gramática Gerativa pressupõe uma compreensão profunda da relação entre a experiência linguística apresentada à criança e a gramática construída com base nessa evidência. O autor pontua, contudo, que nossa compreensão desses fenômenos é bastante limitada, apesar dos avanços em estudos experimentais sobre a aquisição de primeira língua conduzidos dentro do panorama da Gramática Gerativa. Nos casos em que a mudança está em curso, o pesquisador pode examiná-la in loco e, assim, tentar capturar os aspectos desencadeadores do novo estágio da gramática. No caso específico dos estudos da mudança linguística em documentos históricos, se os documentos a registraram, torna-se mais fácil ao pesquisador tentar reconstituir os aspectos desencadeadores do novo estágio da gramática. Certamente, muitos fatores sócio-históricos e culturais influenciam as comunidades de fala e, portanto, o processo de mudança linguística. Do ponto de vista da Gramática Gerativa, porém, o pesquisador costuma abstrair esses fatores e tenta focar sua análise na mudança como uma relação exclusiva entre sistemas gramaticais (cf. ROBERTS; ROUSSOU, 2003). Nesse caso, o pesquisador ignora os registros históricos até onde lhe for permitido (cf. ROBERTS; ROUSSOU, 2003).

A partir do exposto, tem-se que o objetivo crucial deste artigo é sintetizar e refletir acerca dos pressupostos teóricos envolvidos nos conceitos de variação e mudança a partir da perspectiva da Gramática Gerativa. A tarefa proposta consiste em apresentar o tratamento e o desenvolvimento desses conceitos - e de conceitos paralelos a eles - na teoria de Princípios e Parâmetros (P\&P) e no Programa Minimalista (PM). Para isso, o artigo está organizado da seguinte forma: a seção 1 e a seção 2 tratam, respectivamente, da variação paramétrica e da mudança sintática na perspectiva da teoria de P\&P e do PM. Por fim, as considerações finais pontuam as conclusões a que chegamos.

\section{VARIAÇÃO PARAMÉTRICA}

Considerando o problema de Platão, a teoria de P\&P busca fornecer explicações para o rápido e completo processo de aquisição de primeira língua na infância e, por conseguinte, dar uma resposta à diversidade de línguas no mundo. Nessa direção, Chomsky (1986) postulou que a GU é dotada de (i) princípios linguísticos universais às línguas naturais e (ii) parâmetros linguísticos valorados durante o processo de aquisição 
de língua materna. Em P\&P, a tarefa de adquirir a gramática de uma dada língua consiste em preencher as lacunas deixadas abertas pelos princípios da GU, isto é, detectar as configurações dos parâmetros que são compatíveis com o input com o qual a criança é confrontada. Assim, durante a aquisição de primeira língua, a criança testa regras e lança mão de hipóteses, selecionando as estruturas fonológicas, morfológicas e sintáticas que constituem a gramática de sua comunidade linguística. Em suma, a visão de aquisição de primeira língua em P\&P é a de que as crianças, munidas com restrições inatas sobre possíveis gramáticas fornecidas pela GU, são expostas a dados linguísticos primários, isto é, à fala de pessoas, e, assim, desenvolvem sua gramática particular, que é reconhecida em um dado contexto sociocultural como a gramática de uma língua em particular: português, espanhol, inglês etc. Nessa perspectiva, a competência linguística de um falante adulto é vista como o resultado da tradicional dicotomia entre o inato (nature) e o adquirido (nurture), isto é, entre a faculdade da linguagem e a exposição aos dados linguísticos primários (cf. HUANG; ROBERTS, 2016).

Em P\&P, a diversidade linguística é explicada como resultado da valoração de parâmetros distintos para cada língua, exceto no que concerne ao léxico. A variação translinguística é, então, atribuída a diferentes possibilidades de marcação de valores dentro de um conjunto finito de opções paramétricas, fornecidas pela GU durante o processo de aquisição de primeira língua. Assim, na verdade, tanto a variaçãa quanto a mudança em determinada língua podem ser explicadas em termos de parâmetros (cf. LIGHTFOOT, 1979, 1991, 1999; KROCH, 2001; ROBERTS, 2007).

Um exemplo clássico da teoria de P\&P é o Princípio de Projeção Estendida (do inglês Extended Projection Principle - EPP), que, segundo Chomsky $(1981,1982,1986)$, requer que em todas as línguas todas as orações tenham um sujeito. Um parâmetro determina se esse sujeito, quando pronominal, é sempre realizado fonologicamente em contextos finitos (e não finitos). Esse é o parâmetro do sujeito nulo, ou parâmetro pro-drop. Seus efeitos na sintaxe são ilustrados minimamente em (1) - o parâmetro pro-drop deve, na verdade, capturar um agrupamento de efeitos na sintaxe, tais como: sujeitos nulos, inversão livre do sujeito, o efeito that-trace, a distribuição de expletivos etc.

(1) a. (Ella/él) habla español.

b. (Leil lul) parla italiano.

c. ${ }^{*}$ Elle/ it parle français.

d. *(She/he) speaks English.

A abordagem paramétrica da variação translinguística provocou uma intensa agenda de pesquisa sobre as propriedades que os parâmetros manifestam nas línguas naturais. Newmeyer (2013, p. 66, traduzido) enumerou as seguintes propriedades: 
(2) Parâmetros:

a. são descritivamente simples;

b. têm configurações binárias;

c. são pequenos em número;

d. são organizados hierarquicamente/implicacionalmente, tanto para a ordem de aquisição de primeira língua quanto para as generalizações tipológicas;

e. são entidades abstratas com uma rica estrutura dedutiva, possibilitando a predição de propriedades de estruturas morfossintáticas;

f. junto com seu conjunto de configurações possíveis, são inatos (e, portanto, universais);

g. têm configurações que são facilmente aprendidas durante o processo de aquisição de língua;

h. podem sofrer uma mudança rápida (ao contrário dos processos morfológicos e de gramaticalização).

Conforme aponta o autor, P\&P fora o termo-chave para o mainstream dos estudos gerativistas por décadas, tendo em vista que essa teoria apresentava uma solução para a tensão entre as adequações descritiva e explicativa e a realidade da diversidade linguística. P\&P, aliás, representa até hoje um dos modelos mais sofisticados e elegantes de tratamento da variação translinguística (cf. NEWMEYER, 2013; BIBERAUER; ROBERTS, 2017; HOLMBERG, 2017; entre outros). O desdobramento de P\&P no PM por Chomsky $(1993,1995)$, todavia, eliminou boa parte do construto da teoria paramétrica utilizado para tratar da variação. Com o intuito de simplificar a arquitetura da gramática, a concepção binária de parâmetros deixou de possuir um lugar especial para dar conta da variação entre gramáticas. Diferentemente da teoria de P\&P, que não tem suas bases na hipótese lexicalista de Chomsky (1970), o PM passa a associar a variação linguística, incluindo a variação no eixo diacrônico, a propriedades lexicais de uma classe fechada de categorias funcionais que desencadeiam operações sintáticas para licenciar seu conteúdo morfológico (abstrato), incluindo C, T, v e D. Nesta visão, a mudança sintática é identificada por meio das mudanças que afetam o conteúdo dos traços formais das categorias funcionais.

Fuß (2016) e Holmberg (2017) chamam a atenção para o fato de que uma vertente radical no PM diz que a derivação de LF (Forma Lógica, do inglês Logical Form), isto é, a sintaxe estreita, é universal, de modo que a variação linguística estaria, então, restrita à derivação de PF (Forma Fonética, do inglês Phonetic Form), o input para a forma falada ou marcada de uma expressão linguística (cf. BERWICK; CHOMSKY, 2011; BOECKX, 2011). Uma vertente alternativa, por outro lado, diz que a sintaxe permite alguma variação (cf. ROBERTS; HOLMBERG, 2010; HOLMBERG; ROBERTS, 2013; BIBERAUER; ROBERTS, 2017). Em geral, o tratamento teórico da variação no PM restringiu-se: (i) às diferenças na 
especificação dos itens lexicais, ou seja, nos traços formais que constituem os itens lexicais, como: Caso, traços- $\varphi$, traços categoriais, traço-EPP, edge feature etc.; e (ii) ao local onde os traços formais dos itens lexicais são interpretados. Nessa perspectiva, o parâmetro do sujeito nulo pode ser formulado como um traço associado a $T$ finito, que interage com os traços de especificação dos pronomes (cf. HOLMBERG, 2005). Esse tratamento dado à variação no PM está relacionado com a conjectura Borer-Chomsky. Tal conjectura foi proposta por Baker (2008) com base nas seguintes afirmações de Borer e Chomsky, respectivamente:

(a) a variação é restrita às possibilidades que o componente flexional disponibiliza (BORER, 1984, p. 3);

(b) a variação é restrita ao léxico; e no que diz respeito à computação sintática, a uma categoria restrita de propriedades morfológicas, principalmente flexionais (CHOMSKY, 2001, p. 2).

Influenciados pela conjectura Borer-Chomsky, uma tendência recente tem sido concentrar os estudos na variação microparamétrica entre línguas ou variedades de determinada língua. Em vez de propor parâmetros de amplo alcance (macroparâmetros) capazes de dividir as línguas do mundo em classes tipológicas amplas, conforme se vê em Baker (2008), muitos linguistas têm concentrado seus esforços em pesquisar a variação minuciosa entre línguas e variedades relacionadas, a qual pode ser caracterizável por pequenas diferenças no inventário lexical ou na organização categorial (cf. BAKER, 2008; GALVES; CYRINO; LOPES, 2012; HUANG; ROBERTS, 2016). No âmbito dessa discussão, Biberaver \& Roberts (2017) estipulam uma tipologia de parâmetros que não se restringe à dicotomia entre micro e macroparâmetros. A proposta dos autores, que lida tanto com a variação paramétrica quanto com a mudança sintática, é a seguinte (BIBERAUER; ROBERTS, 2017, p. 149, traduzido):

(3) Para um determinado valor $v_{i}$ de um traço parametricamente variável $\mathrm{F}$ :

a. macroparâmetros: todos os núcleos tipicamente relevantes, e.g., todas as sondas (probe), todos os núcleos de fase (phase heads) etc. compartilham $v$;

b. mesoparâmetros: todos os núcleos de dada classe natural, e.g., [+V], ou uma categoria funcional nuclear compartilham $v_{i}$,

c. microparâmetros: uma pequena subclasse lexicalmente definível de núcleos funcionais, e.g., verbos auxiliares modais, clíticos sujeitos, compartilha vi,

d. nanoparâmetros: um ou mais itens lexicais individuais são especificados para $v_{i}$

Biberaver \& Roberts (2017) afirmam que os efeitos dos macroparâmetros estão profundamente enraizados no sistema gramatical, de modo que são facilmente detectáveis nos dados linguísticos primários. Diante disso, eles propõem que os macroparâmetros são 
menos sujeitos a reanálises por adquirentes de primeira língua em condições normais, por isso são considerados diacronicamente mais estáveis. Um exemplo de um macroparâmetro é a harmonia da ordem inicial ou ordem final: a ordem rígida da extremidade do núcleo é estável em muitas línguas e famílias linguísticas, como, por exemplo, nas línguas dravídicas, no japonês e no coreano. Para Biberauer \& Roberts (2017), - contato linguístico extensivo é provavelmente a única maneira pela qual os macroparâmetros mudam.

Os mesoparâmetros, por seu turno, embora sejam difundidos em seus efeitos, são menos definidores do sistema gramatical do que os macroparâmetros e, portanto, são mais suscetíveis à mudança. Os mesoparâmetros, de acordo com Biberaver \& Roberts (2017), tendem a caracterizar grupos linguísticos como as principais subfamílias de uma grande família de línguas, como o indo-europeu. Alguns exemplos de mesoparâmetros são: a ordem VSO nas línguas celtas; o múltiplo fronteamento de sintagmas qu- em línguas eslavas; a ordem V2 - em que o verbo finito ocupa a segunda posição na sentença e a primeira posição é ocupada por qualquer outro elemento - em línguas germânicas, com as exceções do gótico e do inglês moderno; e os sujeitos nulos nas línguas românicas, encontrados em todas as variedades românicas, exceto nas do norte da Europa, incluindo o francês, os dialetos do norte da Itália, o reto-romanche, e no português brasileiro coloquial (BIBERAUER; ROBERTS, 2017). Os pesquisadores argumentam que os mesoparâmetros parecem mais receptivos à mudança induzida por contato linguístico. Eles defendem que as variedades românicas do norte-europeu, como o francês, perderam os sujeitos nulos devido ao contato com línguas germânicas. ${ }^{3}$

Consoante a definição em (3c), microparâmetros afetam subsistemas relativamente pequenos das gramáticas. Como tais, eles são mais suscetíveis a mudanças e representam propriedades da gramática diacronicamente menos estáveis. Os sistemas de clíticos sujeitos dos dialetos do norte da Itália, restritos a um subgrupo do ítalo-romance e do franco-provençal, são exemplos de microparâmetros. Os nanoparâmetros, por fim, são tidos como periféricos ao sistema geral da gramática, representando apenas um punhado de itens lexicais ou apenas um deles. Esses itens mostram o agrupamento de propriedades típicas de todos os parâmetros. Um exemplo é a inversão condicional no inglês moderno

3 Em Borges (2019), utilizamos a tipologia de parâmetros de Biberauer \& Roberts (2017) para afirmar que a variação na sintaxe do sujeito entre o português brasileiro e o português europeu está relacionada ao conceito de mesoparâmetro. Tomamos, ainda, a afirmação dos autores de que a mudança no nível dos mesoparâmetros é causada, principalmente, por mudança induzida por contato linguístico, a fim de verificar alguma relação entre a emergência da gramática do português brasileiro, mais precisamente em Goiás, e o contato linguístico que se instaurou na América portuguesa no período colonial. Defendemos, por fim, que a perda da inversão livre do sujeito (que provocou o enrijecimento da ordem SVO) e de sujeitos nulos (mais especificadamente a mudança de língua de sujeito nulo consistente para língua de sujeito nulo parcial) no português brasileiro podem ser resultado do contato linguístico entre a língua portuguesa e as línguas nigero-congolesas transplantadas para a América portuguesa (cf. BORGES, 2019, para mais detalhes). 
(como em Had I been rich, life would have been great - tradução: 'Tivesse eu sido rico, a vida teria sido ótima'), que afeta apenas três verbos auxiliares: had (passado de have/ter'), should (passado de should/dever') e, marginalmente, were (passado de be/ser/estar') (BIBERAUER; ROBERTS, 2017, p. 150). Nanoparâmetros tendem a ser altamente instáveis, de acordo com Biberaver \& Roberts (2017).

Biberaver \& Roberts (2017) acreditam que a tipologia que eles desenvolvem em (3) pode conciliar a natureza inerentemente abrupta e discreta da mudança paramétrica com o fato de que o registro histórico na maioria das vezes parece mostrar uma mudança gradual. Assim, por exemplo, uma série de mudanças microparamétricas pode dar a aparência de uma mudança mesoparamétrica gradual. Nesses termos, os rótulos macroparâmetro, mesoparâmetro, microparâmetro e nanoparâmetro não se referem a parâmetros distintos, mas ao possível grau de disseminação de um dado traço no sistema gramatical.

Biberaver \& Roberts (2017) desenvolvem sua argumentação em torno de uma perspectiva de aquisição de parâmetros chamada por eles de visão emergente dos parâmetros (do inglês, emergentist view of parameters). Nessa perspectiva, os parâmetros da GU não são pré-especificados na dotação inata, ou seja, eles não fazem parte do $1^{\circ}$ fator proposto por Chomsky (2005). Em vez disso, segundo os autores, os parâmetros emergem da interação de todos os três fatores. Os autores argumentam, ainda, que a GU deixa opções subespecificadas, de modo que as lacunas são preenchidas durante o processo de aquisição de língua pelas crianças, interagindo com os dados linguísticos primários e equipadas com certas estratégias de aquisição de domínio geral.

Por fim, cabe destacar que, assim como parâmetros, a noção de princípios também passou a ser evitada no PM. Chomsky (1995) propôs, por exemplo, que o EPP se reduzisse a um traço D em T. Avançando nessa perspectiva, Chomsky (2015) estabelece uma análise para o EPP e para o Princípio de Categoria Vazia (do inglês, Empty Category Principle ECP) em termos de algoritmo de rotulagem (Labeling Algorithm). Chomsky (2015) considera que uma gama de propriedades excepcionais do sujeito, todas relacionadas ao EPP e ao ECP, e sua variação translinguística constituem um enigma de longa data para a teoria. Desse modo, ele sugere que seria um grande avanço teórico, caso seja alcançado, unificar esses princípios por meio de uma única análise. ${ }^{4}$ Para o pesquisador, existe uma semelhança em ambos os casos EPP e ECP no inglês: na fase de rotulagem, o sujeito deve ser visível, não uma cópia, na posição de SPEC em [C [SPEC-TP]]. Essa observação faz com que Chomsky (2015) sugira que T, em inglês, é fraco para servir como um rótulo, de modo que, com sujeito manifesto, a construção SPEC-TP é rotulada pelos traços de concordância $\{\varphi, \varphi\}$. Assim, desde que T concorde com o sujeito, o movimento do sujeito para [SPEC-TP]

$4 \mathrm{O}$ ECP foi inicialmente postulado na teoria gerativa como uma restrição sintática universal que requer que certos tipos de categorias vazias (isto é, vestígios) sejam apropriadamente regidos (CHOMSKY, 1981). 
estabelece os traços compartilhados de T e o sujeito como o rótulo do conjunto \{DP, TP\}. Por meio do algoritmo de rotulagem, Chomsky (2015) fornece uma motivação independente para a razão pela qual um DP sujeito se move para SPEC-TP. Nessa visão, o inglês e línguas similares satisfazem o EPP (CHOMSKY, 2015).

Chomsky (2015) afirma que o ECP parece ser livremente violado nas línguas de sujeito nulo e que a diferença paramétrica entre elas e as línguas do tipo do inglês pode ser atribuída à riqueza morfológica daquelas. Desse modo, o $\mathrm{T}$ do italiano, com morfologia verbal rica, pode rotular TP e também \{SPEC, TP\}; como vimos, no caso do inglês, língua com concordância verbal fraca, isso não é possível, de modo que SPEC-TP deve estar visível quando o algoritmo de rotulagem se aplica (CHOMSKY, 2015). Assim, Chomsky (2015) conclui que o italiano não se comporta da mesma maneira que o inglês em relação ao EPP e ao ECP. Chomsky (2015) conclui, a partir de sua análise, que o italiano não tem EPP, assim como não está em conformidade com o ECP, unificando assim o EPP e o ECP, presentes no inglês, por meio do algoritmo de rotulagem e mantendo a diferença paramétrica do italiano em relação ao inglês em termos de riqueza de concordância. Chomsky (2015) observa, ainda, que o movimento do sujeito para SPEC-TP não está bloqueado no italiano; ele só não seria necessário. Isso, aponta o autor, deixa em aberto uma série de questões sobre exatamente onde o sujeito e o VP estão quando o sujeito não é projetado para SPEC-TP, o que não será debatido neste trabalho por questões de espaço e escopo.

\section{MUDANÇA SINTÁTICA}

Pires \& Lightfoot (2003) confirmam que os estudos de Klima (1964) e Closs (1965) foram os primeiros a tratar da mudança em sistemas gramaticais a partir da Gramática Gerativa: Klima (1964), ainda dentro do modelo da gramática gerativo-transformacional, concluiv o primeiro estudo extensivo em sintaxe diacrônica a partir de dados de movimento qu-, marcação de caso e reanálise lexical em estágios do inglês; Closs (1965), por sua vez, apontou a descontinuidade como uma questão central entre as gramáticas de uma geração para outra. Lightfoot (1979) foi, contudo, quem primeiro associou a mudança sintática aos dados linguísticos primários aos quais - antes de introduzir quaisquer mudanças no sistema gramatical - as crianças de uma nova geração de falantes são expostas (cf. PIRES; LIGHTFOOT, 2003; LIGHTFOOT, 2017a). A vinculação entre mudança gramatical e aquisição de língua foi formulada, portanto, na obra seminal de Lightfoot (1979), Principles of diachronic syntax. Pela primeira vez, a compreensão da mudança gramatical passou a ser estritamente ligada à elaboração de teorias restritivas da gramática, que poderiam definir os limites da variação e, por consequência, o possível resultado da mudança, dada uma certa experiência desencadeadora. 
Lightfoot (1979) integrou as preocupações da pesquisa em sintaxe diacrônica com as da Gramática Gerativa ao postular que a mudança gramatical é impulsionada pela reanálise dos dados linguísticos primários na aquisição de primeira língua, de modo que o resultado pode ser uma nova geração poder gerar uma nova gramática para uma determinada língua. Uma das principais ideias propostas por Lightfoot (1979) foi o Princípio de Transparência, segundo o qual as derivações transformacionais eram limitadas no grau de opacidade que elas poderiam induzir. Se determinados traços de uma gramática se tornassem muito opacos, o Princípio de Transparência forçaria uma reanálise, isto é: os traços opacos são eliminados e a nova análise, mais transparente, produz mudanças. Lightfoot (1979) postulou o Princípio de Transparência como um princípio da gramática, isto é, uma condição geral sobre a natureza das derivações.

Ao tratar da história do Princípio de Transparência, Lightfoot (2017a) retoma seus achados em Lightfoot (1979, ̧ु4.1) e o exemplifica a partir de dados de quantificadores do inglês (all, any, each, both, every etc.), que costumavam ter a mesma distribuição que os adjetivos no inglês antigo e médio. Ambas as categorias, segundo Lightfoot (2017a), pertenciam a uma supercategoria rotulada de modificadores. Com o passar do tempo, a distribuição dos modificadores que viriam a ser quantificadores permaneceu constante, mas os modificadores que se tornariam adjetivos modernos desenvolveram novas propriedades. No final do século XV, modificadores destinados a se tornarem adjetivos tornaram-se mais restritos em sua distribuição: não podiam mais ocorrer livremente diante de um determinante, com um genitivo ou com um nominal. Para Lightfoot (2017a), isso sugere que os modificadores acumularam gradualmente três características de exceção, impedindo tais ocorrências. Posteriormente, isto é, no final do século XVI, ocorreram as seguintes mudanças:

(4) a. alle both aparecem com partitivos of,

(LIGHTFOOT, 2017a, p. 327, traduzido)

b. obsolescência do determinante-quantificador-substantivo;

c. obsolescência de múltiplos quantificadores em sequência;

d. obsolescência do adjetivo-determinante-substantivo;

e. obsolescência de adjetivos pós-nominais;

f. obsolescência de adjetivos usados como nominais.

O autor argumenta que, como os modificadores pré-adjetivos e pré-quantificadores passaram a divergir em sua distribuição, havia uma boa razão para os adquirentes de língua postularem que eles eram diferentes categorias: adjetivos ocorriam à esquerda de um substantivo ou seguindo um verbo de cópula, como ilustrado em (5), enquanto quantificadores ocorriam como o especificador de um DP ou em uma posição determinante com um complemento NP ou PP, como ilustrado em (6). 
(5) a. ${ }_{\mathrm{NP}}\left[\mathrm{Ared}_{\mathrm{NP}}[\right.$ books $]$

(LIGHTFOOT, 2017a, p. 328)

b. vp[vbecome Aangry $]_{3}$

(6) a. $\mathrm{DP}\left[\mathrm{spec}_{\mathrm{p}} a / \mathrm{DP}_{\mathrm{DP}}[\right.$ his apples] $]$

(LIGHTFOOT, 2017a, p. 328)

b. DP[D both ${ }_{\mathrm{NP}}[$ books about taxes]], $\mathrm{DP}[\mathrm{Dal} / \mathrm{PP}[$ of the books $]$

Essas estruturas, segundo Lightfoot (2017a), mostram que (4a) pode ser gerado, mas (4b-f) não. A reanálise gramatical aparece aí como um efeito do Princípio de Transparência: os traços opacos foram eliminados e a nova análise, mais transparente, produziu mudanças.

Ao adaptar sua abordagem sobre a mudança sintática ao modelo de P\&P, Lightfoot (1991, 1999) assume que a mudança sintática envolve a redefinição dos valores dos parâmetros, haja vista a teoria de P\&P considerar a gramática das línguas naturais como resultado da fixação de parâmetros de uma determinada língua gerada por um sistema computacional com princípios imutáveis. Assim, o pesquisador postula que os parâmetros são redefinidos no decurso da aquisição de primeira língua, presumivelmente com base na reanálise dos dados linguísticos primários pelos adquirentes de primeira língua. Para Lightfoot (1991,1999), a mudança é iniciada quando uma população de aprendizes converge em um sistema gramatical que difere em pelo menos um valor de parâmetro do sistema internalizado dos falantes cujo comportamento linguístico fornece a entrada para os aprendizes. Como a geração mais jovem substitui a mais antiga, a mudança é realizada por meio da comunidade de fala. Em resumo, Lightfoot $(1991,1999)$ assume que a mudança sintática é um aspecto do processo de marcação de parâmetros durante a aquisição de primeira língua e, portanto, está intrinsecamente ligada à língua-l.

A teoria de P\&P representa, assim, um modelo teórico que pode explicar tanto os agrupamentos de propriedades sincrônicas da gramática quanto os agrupamentos de propriedades diacrônicas. Nessa direção, muitos pesquisadores trabalhando com linguística histórica e linguística gerativa estavam convencidos de que todos os principais tipos de mudança sintática podiam ser reformulados em termos de operações de reanálise de parâmetros, que pareciam ser o principal mecanismo explicativo da mudança sintática (cf. ROBERTS, 2007; MADARIAGA, 2017). A interpretação da mudança gramatical como um exemplo particular de reanálise de parâmetros, isto é, como um fenômeno conduzido pela aquisição de língua, refuta qualquer teoria de mudança que recorre a explicações envolvendo mais de uma geração. No entanto, considerando uma comunidade de falantes monolíngues e homogênea, essa explicação parece levar a um paradoxo: como uma gramática alvo $G$ pode produzir na nova geração um output que difere significativamente do input que levou à aquisição de $\mathrm{G}$ na geração anterior? Isso é, às vezes, chamado de 
problema lógico da mudança gramatical, a versão gerativista para o problema da implementação de Weinreich, Labov \& Herzog (1968) (cf. ROBERTS, 2007; WALKDEN, 2017).

Postular que a mudança sintática ocorre durante o processo de aquisição de primeira língua implica considerar que os dados linguísticos primários não são, a priori, suficientes para a marcação de todos os valores paramétricos de uma dada língua - ainda que, paradoxalmente, se deva admitir que, independentemente de os dados serem insuficientes, uma opção paramétrica tem de ser escolhida (ROBERTS, 2007). Ademais, esse postulado reforça o papel do aparato genético da linguagem humana ao considerar as intuições de que uma criança lança mão quando os dados linguísticos primários the são apresentados (cf. LIGHTFOOT, 1979, 1991, 1999, 2006; KROCH, 2001, 2005; ROBERTS; ROUSSOU, 2003; ROBERTS, 2007; entre outros). Ao asseverar que uma opção paramétrica tem de ser escolhida, enfatiza-se também o fato de que o processo de aquisição de língua é, primordialmente, caracterizado pela fixação de parâmetros. Assim, não há possibilidade de não se marcar um parâmetro da GU - e, uma vez que um parâmetro é marcado, não há como desmarcá-lo (cf. KROCH, 2005; ROBERTS; ROUSSOU, 2003; ROBERTS, 2007). Nessa perspectiva, a mudança na gramática de uma língua não é entendida a partir de concepções como frequências, clines (gradações), continua e tendências, mas, outrossim, como mudança na marcação de opção paramétrica (cf. KROCH, 2005; ROBERTS, 2007).

Madariaga (2017) chama a atenção para o fato de que nem todos os estudos diacrônicos concordam com a explicação da ambiguidade estrutural para haver a reanálise dos dados linguísticos primários (cf. ROBERTS, 2007), pois é altamente contestável que uma nova estrutura apenas possa surgir com base numa ambiguidade que somente é detectada uma vez que a mudança ocorreu, ou seja, após a reanálise. Um exemplo que fornecemos nessa direção é o das construções com se-impessoal e com sujeitos nulos indefinidos na $3^{a}$ pessoa do singular no português brasileiro: este caso, ilustrado em (7b), só pôde ser analisado como ambíguo em relação àquele, exemplificado em (7a), porque sua interpretação impessoal surgiu abruptamente na gramática da língua - em trabalho anterior, propusemos que o surgimento de (7b) no português brasileiro é resultante de uma mudança paramétrica de língua de sujeito nulo consistente para língua de sujeito nulo parcial, que permite o licenciamento de sujeitos nulos indeterminados na $3^{\text {a }}$ pessoa do singular devido à ausência de um traço de definitude no núcleo funcional temporal (cf. BORGES, 2019, para mais detalhes).

(7) a. Vende-se casas

b. Vende casas.

Roberts (2007) e Biberaver \& Roberts (2017) defendem, contudo, que um certo grau de ambiguidade dos dados é necessário para que a mudança ocorra. Roberts (2007) recorre 
à $G U$ e à parametrização para defender seu ponto de vista: a GU restringe a gama de ambiguidades potenciais nos dados linguísticos primários, nos quais diferentes parâmetros possíveis podem ser definidos durante o processo regular de aquisição de primeira língua. Biberaver \& Roberts (2017), com base na noção de parâmetro em (3), afirmam que, se um valor definido $v_{i}$ é inequivocamente expresso para um parâmetro $p_{i}$ nos dados linguísticos primários, então os adquirentes irão convergir com sucesso em $v_{\text {i }}$ Ou seja, o parâmetro não será alterado se não houver ambiguidade - esse fenômeno, aliás, é chamado de Princípio de Inércia: "as coisas ficam como estão a não ser que uma força atue sobre elas" (cf. KEENAN, 2002; LONGOBARDI, 2001; BIBERAUER; ROBERTS, 2017). Por outro lado, a mudança gramatical ocorre quando há um valor inovador $v_{i}$ de um parâmetro $p_{k}$, isto é, uma propriedade lexical, um traço vinculado a determinada categoria funcional, que é por algum motivo mais acessível nos dados do input do que o relevante valor $v_{i}$ que é parte da gramática alvo (FUß, 2016).

Ressalta-se que, nessa perspectiva, a reanálise não é algo que os falantes adultos fazem em suas línguas maternas. A reanálise ocorre com o input recebido por um adquirente, ou seja, é uma das maneiras de as crianças adquirirem suas gramáticas. A diferença crucial entre gramáticas sem reanálise e gramáticas reanalisadas é que, no caso das primeiras, a gramática do adquirente converge com a gramática que forneceu os inputs, enquanto, no caso das segundas, a nova gramática não converge com aquela que forneceu os dados linguísticos primários (cf. LIGHTFOOT, 1991, 1999; MADARIAGA, 2017). Tanto as gramáticas convergentes quanto as que não convergem são iguais na medida em que devem ser adquiridas novamente de acordo com o procedimento usual de aquisição de língua, ou seja, com base nos dados linguísticos primários, o input disponível em um ambiente linguístico (MADARIAGA, 2017). Madariaga (2017) afirma que a não convergência de gramáticas tem sido chamada de falha na transmissão ou descontinuidade - os termos não são tomados aqui como sinônimos.

Anthony Kroch (1946-2021) foi um dos grandes pesquisadores que defendeu que a mudança gramatical é provocada por uma falha na transmissão linguística durante o processo de aquisição de língua materna. Mais precisamente, para Kroch (2001), a mudança gramatical é resultante de uma falha de aprendizagem. Kroch (2001) argumenta que o entendimento do que vem a ser uma falha na transmissão de traços linguísticos é limitado, pois não se pode precisar a relação entre a evidência apresentada ao aprendiz e a gramática adquirida. Argumenta, ainda, que a mudança sintática decorrente de uma falha na transmissão também pode ser provocada por adultos aprendizes de segunda língua, principalmente nos casos de contato linguístico. Para o autor, na verdade, nos casos de contato e aquisição de segunda língua, pressupõe-se que a aquisição da nova língua é naturalmente imprecisa. 
Kroch (2001) pondera que, no percurso diacrônico de uma dada língua, a variação pode ser encontrada em textos particulares de um único indivíduo. Ele argumenta que um indivíduo pode ter mais de uma gramática para o que é, em termos socioculturais, uma única língua ou registro. Em outras palavras, um único falante de uma dada língua pode ter mais do que uma língua-I. Esse falante, inclusive, pode usar essas línguas-I distintas num mesmo registro ou contexto sociolinguístico (KROCH, 2001). Sob esse ponto de vista, diferentes registros da mesma língua que um único falante pode ter dominado podem justificar a postulação de mais de uma língua-l em estudos diacrônicos de uma determinada língua, nos mesmos termos assumidos para os casos de bilinguismo. Kroch (2001) defende que os seres humanos são capazes de rastrear a frequência dos eventos linguísticos em seu ambiente, por isso, ele propõe que, em determinado momento do percurso histórico de uma língua, uma das gramáticas-I em competição vai suplantar a outra - as razões para que uma determinada gramática-I prevaleça ainda são incertas, segundo Kroch (2005). O autor, no entanto, parece rechaçar a ideia sociolinguística que atrela a variação no uso por indivíduos à mudança sintática.

Kroch (2005) defende a tese de que um aprendiz define um parâmetro "erroneamente" porque certos dados foram ignorados ou não encontrados durante o processo de aquisição de língua, ou porque foram ouvidos pelo aprendiz e tratados por ele como possíveis formas da gramática alvo - segundo o autor, se os erros ouvidos pelo aprendiz são incompatíveis com a GU ou outras retrições ligadas à linguagem adulta, a aquisição desses erros como parâmetros, naturalmente, não acontece. Os parâmetros adquiridos "erroneamente" pelo aprendiz são compatíveis com a GU, pois refletem propriedades de outras línguas. Esse aprendiz, contudo, ainda pode aprender os parâmetros da língua de sua comunidade linguística (isto é, os parâmetros da geração antiga) "corretamente", mas apenas da maneira com que ele aprende outro idioma ou dialeto, qual seja, adicionando conhecimento ao invés de substituir um parâmetro por outro. O resultado disso é o que Kroch (2005) chama de bidialetismo em relação ao parâmetro aprendido primeiramente. O bidialetismo de Kroch (2005) decorre, portanto, da aquisição imperfeita de um traço linguístico (parâmetro adquirido "erroneamente") e da posterior aquisição do traço linguístico (parâmetro) "correto". Assim, o bidialetismo de Kroch (2005) apresenta as seguintes características em seu percurso diacrônico:

\footnotetext{
Bidialectalismo causado por erro de aprendizagem e correção é a fonte, no modelo de transmissão imperfeita aqui desenvolvido, da mudança sintática. Por pelo menos uma razão, o processo de correção de parâmetros adquiridos erroneamente não pode ser infalível. Se uma criança ouve a língua produzida por outra que tenha um parâmetro "incorreto", então a criança que escuta terá, na verdade, uma evidência positiva da configuração incorreta e pode ser induzida a definir o parâmetro incorretamente. Qualquer viés no sistema que favoreça a configuração incorreta pode, sob circunstâncias apropriadas, favorecer a disseminação eventual da configuração originalmente incorreta. [...] Uma vez que a mudança sintática esteja em andamento, o adquirente ouvirá evidências na comunidade de fala sobre configurações mutuamente inconsistentes e aprenderá ambas. No decorrer do tempo histórico, uma
} 
configuração provavelmente vencerá a outra, por razões que ainda não são bem compreendidas. [...] (KROCH, 2005, p. 3, traduzido). ${ }^{5}$

Observa-se que, nos casos de bidialetismo em perspectiva diacrônica, um cenário linguístico gradualmente ganha espaço sobre o outro - mais especificadamente, se o parâmetro adquirido "erroneamente" é comum na linguagem infantil, então a probabilidade de ele provocar a mudança sintática é substancial. Kroch (2005) defende, portanto, que as formas que dão evidências para ambas as configurações paramétricas nos casos de bidialetismo aparecem com frequência e todos os aprendizes podem adquirir e usar ambas as configurações. No decorrer do tempo, todavia, a frequência de uma das duas formas cai até, finalmente, ela ocorrer muito raramente para permitir sua aquisição pelas gerações futuras. Desse modo, instaura-se a instabilidade de um dos parâmetros na gramática.

Kroch (2005) defende, ainda, que, nos casos de aquisição de língua materna, a convergência da gramática da criança com a gramática do adulto é probabilística: "dada uma população de adquirentes, haverá erros com uma distribuição de probabilidade que depende da força da evidência para determinadas propriedades gramaticais e da variação nos dados primários aos quais os aprendizes estão expostos" ( $\mathrm{KROCH}, 2005$, p. 1-2, traduzido). Kroch (2005) reconhece que o principal problema dessa abordagem é que é impossível saber se os erros de aprendizagem são suficientemente comuns para servir como uma importante causa da mudança. ${ }^{6}$

Kroch (2005) contrapõe o modelo de transmissão imperfeita entre gerações com o modelo de deriva interna, segundo o qual a mudança está condicionada a uma mudança gradual na frequência dos usos das formas linguísticas, de maneira que, se a frequência de uma forma linguística cai abaixo do limite capaz de propiciar o aprendizado, a mudança gramatical ocorre (cf. NARO; SCHERRE, 2007, para uma discussão sobre o modelo de deriva interna utilizando a formação do português brasileiro como exemplo). Para Kroch (2005), o modelo de transmissão imperfeita explica melhor a mudança, pois se baseia no fato de que ela começa, realmente, com uma mudança na gramática, a qual é responsável por sua propagação na comunidade de fala e pela frequência com que certas formas linguísticas são usadas. Sob esse ponto de vista, a gradualidade nos dados históricos não

5 No original: "Bidialectalism due to mislearning and correction is the source, in the imperfect transmission model as developed here, of language change. For at least one reason the process of correction of misset parameters cannot be infallible. If one child hears language produced by another that has misset a given parameter, then the listening child will actually get positive evidence for the incorrect setting and may be induced to itself set the parameter incorrectly. Any bias in the system that favors the incorrect setting may, under appropriate circumstances, favor the eventual spread of the originally incorrect setting. [...] Once language change is in progress, the learner will hear evidence in the speech community for mutually inconsistent settings and learn both. Over historical time, one setting is likely to win out over the other, for reasons that have yet to be well understood. $[\ldots]$.

6 No original: "Given a population of learners, there will be errors with a probability distribution that depends on the strength of the evidence for given grammatical properties and on variation in the primary data that learners are exposed to." (KROCH, 2005, p. 1-2) 
representa imprecisão, mas, sim, duas entidades distintas na mente dos falantes, uma substituindo gradualmente a outra.

A abordagem de Kroch $(2001,2005)$ para a mudança sintática gira em torno da chamada competição de gramáticas, que busca fornecer uma explicação para a opcionalidade vista em textos produzidos pelos falantes de uma dada língua (cf. KROCH, 1989, 2001, 2005). Nessa hipótese, quando uma mudança está ocorrendo em uma dada língua, alguns falantes têm acesso a duas variantes diferentes da mesma forma ou estrutura, uma variante antiga e uma recém-criada, inovadora. Os falantes que exibem as duas variantes, na verdade, exibem duas gramáticas diferentes (diglossia) e recorrem à alternância de código enquanto usam uma ou outra, da mesma maneira que os bilíngues fazem com suas diferentes línguas. ${ }^{7}$ No Brasil, a proposta de competição de gramáticas, empregada com um elegante ferramental estatístico, tem fornecido estudos frutíferos nos projetos coordenados por Charlotte Galves, da Universidade Estadual de Campinas, com base no Corpus Histórico do Português Tycho Brahe (cf. GALVES; ANDRADE; FARIA, 2017).

Biberaver \& Roberts (2017) lembram que uma explicação complementar para uma visão de diglossia sobre gramáticas concorrentes é que elas podem coexistir em um falante porque pertencem a diferentes níveis linguísticos. Isto é, a existência de duas variantes nas produções linguísticas pode sinalizar que uma das variantes pertence à competência linguística do falante (língua-l), enquanto a outra é externa a essa competência, uma variante usada episodicamente no conjunto de enunciados produzidos por uma comunidade linguística, também chamada de língua-E (externa, extensional). Um exemplo é o uso do chamado se-passivo, restrito à escrita padrão no Brasil (cf. MARTINS; NUNES, 2016), em contraste com os mencionados se-impessoal e sujeitos nulos indeterminados na $3^{a}$ pessoa do singular, presentes na escrita e na fala do português brasileiro (8b-c). Nesse sentido, o uso do se-passivo em textos contemporâneos do português brasileiro, como em (8a), deve ser tomado como enunciado exclusivo da língua-E.

(8) a. Vendem-se casas. (Se-passivo).

b. Vende-se casas. (Se-impessoal).

c. Vende casa. (Sujeito nulo indeterminado).

7 Em Roeper (1999), a ideia de competição de gramáticas pode ser entendida como bilinguismo universal. Sua assunção fundamental é a de que escolhas aparentemente contraditórias em uma dada língua, dentro do contexto da opcionalidade versus a obrigatoriedade, são gramáticas em competição. O autor propôs que cada falante gera um conjunto de minigramáticas que os torna universalmente bilíngues em sua própria língua materna. Roeper (1999, p. 173) exemplifica que o inglês, uma língua não pro-drop, apresenta um registro informal, conhecido como diary drop, em que os sujeitos oracionais são omitidos: "seems like a good idea"|"looks good to me". 
Conforme vimos, os estudos em linguística gerativa propõem que o objeto apropriado do estudo científico da linguagem humana é a língua-l, que é geralmente contrastada com a língua-E, que se resume ao conjunto de expressões reais ou potenciais que estão em uso em uma comunidade linguística - assim, evidências linguísticas consistem em dados da língua-E. O objetivo de uma pesquisa em sintaxe diacrônica, portanto, é detectar as propriedades da língua-I, inspecionando o comportamento linguístico dos indivíduos (FUß, 2016). Desse modo, qualquer princípio da GU - interpretada como uma teoria dos universais formais que identifica o conjunto de possíveis gramáticas das línguas naturais - e/ou regra de gramática que sejam postulados devem ser vistos como parte da língua-I. Adotar essa visão implica afirmar que o objeto apropriado da linguística histórica formal deve ser a(s) língua(s)-I ou a(s) gramática(s)-I (FUß, 2016).

Fuß (2016) e Lightfoot (2017b) afirmam que uma perspectiva de língua-I sobre a mudança sintática evidencia o fato de que a aquisição de língua entre uma geração de falantes e outra é necessariamente descontínua - termo que essencialmente se associa a uma propriedade externa das línguas humanas e que, conceitualmente, consideramos diferente da noção de transmissão linguística (imperfeita). Dizer que a descontinuidade é uma propriedade externa às línguas humanas a vincula ao conjunto de princípios e restrições que integram o terceiro fator do design das línguas humanas. Compreende-se a descontinuidade, portanto, como a emergência de uma nova língua-I - em uma nova geração de falantes - desencadeada por novas evidências de língua-E, ou seja, por novos dados linguísticos primários quando comparados com aqueles que geraram a língua-I da geração anterior de falantes de uma dada língua (LIGHTFOOT, 2017b).

Nessa perspectiva, durante o processo de aquisição de primeira língua, as crianças não têm acesso direto às propriedades (abstratas) da gramática alvo; em vez disso, elas constroem uma gramática baseada nos dados linguísticos primários que recebem, os quais são potencialmente diferentes e novos em relação àqueles que geraram a gramática da geração anterior. Desse modo, a mudança sintática expressa na gramática da nova geração ocorre não porque traços linguísticos deixaram de ser transmitidos ou não foram adequadamente aprendidos no decorrer do processo de aquisição de língua, mas porque os dados linguísticos primários eram novos em relação àqueles que geraram a gramática da geração anterior. Vejamos a figura 1. 


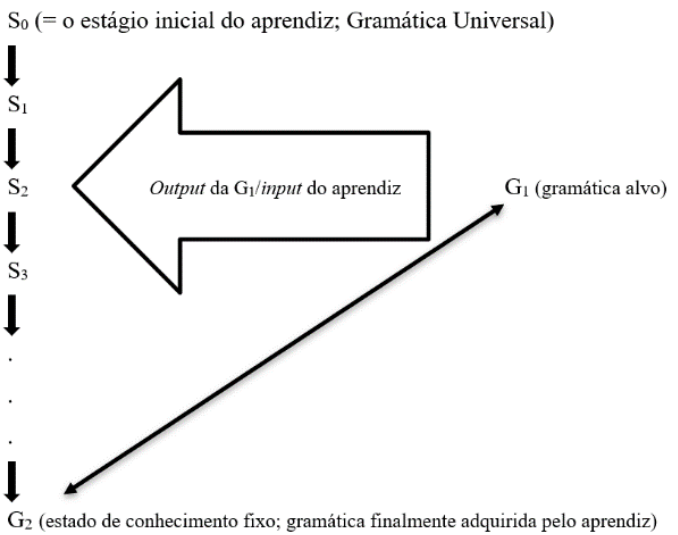

Figura 1. Modelo de aquisição e mudança linguística.

Fonte: Fuß (2016, p. 463, traduzido)

Legenda: So (estágio inicial); S (estágio 1); $S_{2}$ (estágio 2); $S_{3}$ (estágio 3); $G_{1}$ (gramática 1); $G_{2}$ (gramática 2).

A respeito do modelo na figura 1, Fuß (2016) explica que a criança adquirente de primeira língua, partindo do estado inicial da gramática $\left(S_{0}\right)$, ou seja, daquilo que é considerado uma expressão dos genes modelado em termos de um sistema de princípios abstratos, constrói um número de estágios intermediários de conhecimento $\left(S_{1}, S_{2}, S_{3} \ldots\right)$ durante o processo de aquisição de primeira língua com base nas evidências fornecidas pelo input da gramática da geração anterior. Esses estágios são sempre atualizados assim que a criança aprendiz toma conhecimento de evidências necessárias para ativar uma nova propriedade da gramática, cujas propriedades não necessariamente convergem com a gramática da geração anterior. O processo de construção de uma dada gramática chega, por fim, a um estado de conhecimento fixo, o qual representa a gramática adquirida pela criança no decorrer do processo de aquisição de primeira língua (FUß, 2016).

Lightfoot (2017b) argumenta que a descontinuidade não pode ser tomada como um evento especial, mas como o estado normal daquilo que confronta qualquer criança durante o processo de aquisição de primeira língua. Assim, as línguas-E são o locus da mudança no processo de aquisição de primeira língua, e as línguas-I, em particular, são geradas em cada nova geração e em cada indivíduo. Nessa perspectiva, o pesquisador pode vincular aspectos particulares das línguas-E às novas línguas-I. Para Lightfoot (2017b), se o trabalho sobre mudança fornece uma visão sobre a vinculação de aspectos específicos das línguas-E às novas línguas-I, isso constitui uma contribuição importante para a compreensão da aquisição de língua, o que, para o autor, ainda não foi alcançado pela pesquisa experimental.

Lightfoot (2017b) afirma ser impossível que duas crianças recebam idênticos dados linguísticos primários, pois elas naturalmente ouvem coisas distintas. No entanto, apesar da variação na experiência, as crianças vão, muitas vezes, convergir suas línguas-I no que diz respeito ao conjunto de estruturas sintáticas adquiridas. Lightfoot (2017b) pondera, ainda, que os dados linguísticos primários podem variar em diferentes modos no processo 
de aquisição de uma dada nova geração e, ainda assim, não conceber novas línguas-l. As experiências individuais podem variar indefinidamente, mas as línguas-I dentro de uma comunidade linguística mostram estabilidade estrutural e variam limitadamente. Conforme salienta Chomsky (2015), numa dada comunidade linguística, as línguas-I podem não ser inteiramente idênticas, mas se sobrepõem substancialmente.

De acordo com Lightfoot (2017b, 2017c), por meio do conceito de descontinuidade, a mudança gramatical é entendida também como um fenômeno mais individual que pode afetar a experiência linguística de outros e levar a uma mudança no comportamento de toda a comunidade linguística. Esse seria o caso, por exemplo, dos falantes bilingues de inglês escandinavo que teriam desencadeado uma mudança generalizada na gramática do inglês médio, nomeadamente, a perda da morfologia verbal (cf. LIGHTFOOT, 2017b, 2017c). Nessa perspectiva, novas línguas-E também resultam do contato linguístico e do bilinguismo, e línguas-E resultantes do contato linguístico e do bilinguismo também geram novas línguas-l.

Lightfoot (2017b, 2017c) menciona a perda maciça da morfologia verbal no inglês médio como um dos resultados do estreito contato dos falantes de inglês com os falantes escandinavos no norte da Inglaterra, mais precisamente pelo bilinguismo inglêsescandinavo, no qual os indivíduos com as línguas-l inglesa e escandinava apresentavam inicialmente um sistema morfológico rico para cada língua, semelhantes entre si, mas diferentes e não adquiridos como um único sistema (LIGHTFOOT, 2017b). Lightfoot (2017c) menciona que o inglês primitivo tinha propriedades morfológicas complexas e que naquele período era possível encontrar:

(a) as conjugações fremme, fremst, fremp e fremmap no tempo presente e fremed, fremedest, fremede e fremedon no passado de do/'fazer';

(b) as conjugações se ${ }^{-}$, siehst, siehpe se-op no tempo presente de see/ver';

(c) as conjugações $r r^{-} d e, r{ }^{-} t s t$, ri'tt e $r i^{-} d a p$ no tempo presente e $r a^{-} d$, ride, ra-de ridon no pretérito de ride/'montar'.

A partir de determinado período de contato linguístico e bilinguismo, no entanto, registra-se que, diferentemente da maioria das línguas europeias, o inglês mudou drasticamente seu paradigma flexional, restando apenas a conjugação -s/-epda $3^{\text {a }}$ pessoa do singular do tempo presente. Lightfoot (2017c) mostra também que, nos primórdios do inglês moderno, verbos auxiliares modais do tipo can, could, must, may, might, will, would, shall, should e do, perderam o movimento do verbo para Infl e foram recategorizados como itens de Infl, conforme exemplificado, respectivamente, em (9a) e (9b). O autor menciona que, por determinado período, ambos os sistemas coexistiam e possivelmente competiam entre si: verbos como can eram gerados em VP e moviam-se para Infl ou eram gerados 
diretamente em Infl. Com o tempo, entretanto, (9a) tornou-se rara, e (9b) mais produtiva, vindo a se estabilizar. ${ }^{8}$

(9)

a. IP<smiles>C1CCC1</smiles>

Spec IP<smiles>CCCCC</smiles>

I

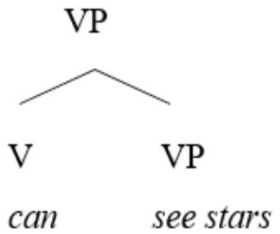

b. IP

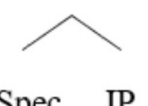

Spec IP

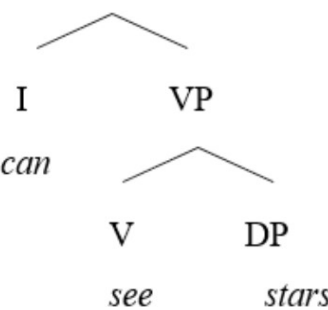

Com base nessas evidências, Lightfoot (2017c) supõe que diacronicamente as línguasE que as crianças ouviram mudaram de tal forma que auxiliares modais modernos como can, may, shall etc. vieram a ser morfologicamente distintos de outros verbos, até porque eles nunca possuíram a única característica restante da morfologia verbal do tempo presente, a terminação - $s /-e p$ da $3^{a}$ pessoa do singular. Ademais, Lightfoot (2017c) mostra que as formas do tempo passado desses verbos (could, would, might, etc.) tinham significados que não eram tempo passado, refletindo antigos usos subjuntivos: "They might/could/would leave tomorrow". Para o autor, essas evidências indicam que esses verbos modais foram recategorizados na gramática interna dos falantes, porque se tornaram formalmente distintos de outros verbos como resultado da simplificação morfológica dos verbos. Houve, assim, o que Lightfoot (2017c) chama de efeito dominó: mudanças no que as crianças ouviram e a morfologia do verbo recentemente reduzida levaram a uma categorização diferente de certos verbos. Em outras palavras, na história do inglês, novas línguas-E resultantes do contato linguístico e do bilinguismo entre falantes de inglês e escandinavo acionaram novas línguas-I com morfologia verbal reduzida e verbos modais do tipo can recategorizados como itens de Infl. Aí constam, de acordo com Lightfoot (2017b), a descontinuidade e sua explicação, ambas evidenciando que não há aprendizado imperfeito ou transmissão imperfeita, apenas novas línguas-E acionando novas línguas-I.

8 A partir da constatação de que, no inglês médio, havia uma distinção entre a sintaxe V2 do sul e a sintaxe V2 do norte e do leste da Inglaterra, Kroch, Taylor \& Ringe (2000) propõem que a sintaxe V2 inovadora surge como uma consequência da perda das flexões verbais no inglês médio do norte. A perda da concordância rica, por sua vez, é considerada por esses autores um resultado da aquisição imperfeita do inglês pelos invasores escandinavos, que formavam uma proporção suficientemente grande da população do norte naquele período da língua para impor efeitos de substrato ao dialeto do norte. 


\section{CONSIDERAÇÕES FINAIS}

Neste trabalho, discutimos três propriedades inerentes às línguas humanas: elas fazem parte de uma dotação inata da espécie humana, variam e mudam com o tempo. Tratamos mais detidamente dos conceitos de variação e mudança. Vimos que, na teoria de P\&P, a variação esteve relacionada essencialmente às diferentes marcações paramétricas disponíveis no processo de aquisição de primeira língua e às idiossincrasias do léxico. $A$ mudança sintática, por outro lado, estava vinculada a diferentes marcações paramétricas reanalisadas durante o processo de aquisição de primeira língua de uma nova geração. Mostramos que a noção de mudança sintática dentro da Gramática Gerativa restringe a mudança a um conjunto de diferenças discretas entre a gramática alvo e a gramática adquirida pelo aprendiz. Argumentamos que, a partir dessa perspectiva, se pode melhor compreender o funcionamento da aquisição de primeira língua e descobrir restrições a possíveis mudanças impostas pelas propriedades da GU.

Considerando o PM, mostramos que os pesquisadores passaram a enxergar o locus da variação nas diferentes especificações dos itens lexicais e no local onde os traços formais desses itens lexicais são interpretados. Explicamos que a mudança sintática é extremamente sistemática, em contraste com outros tipos de mudança, que são esporádicos e geralmente confinados a um único elemento lexical (cf. LEDGEWAY; ROBERTS, 2017; i.e., os artigos publicados na obra). Vimos também que a pesquisa diacrônica recente se firma no pressuposto de que a mudança gramatical ocorre devido a uma descontinuidade provocada naturalmente pela aquisição de primeira língua por meio de dados da língua-E. Quer dizer, alguns estudiosos concordam com a proposta de que a mudança gramatical deve ser atribuída à descontinuidade, caracterizada por contingências impostas pelo contexto social. Esse pressuposto vincula a mudança gramatical e o processo de aquisição de língua e presumivelmente condiciona seus resultados ao imperativo epistemológico de que todas as especificações gramaticais das línguas humanas se adaptam às especificações da Gramática Universal. Nessa perspectiva, nem as línguas-E nem as línguas-I são transmitidas - imperfeita ou perfeitamente.

\section{AGRADECIMENTOS}

Esta pesquisa contou com fomento da Capes (Código de Financiamento 001 \& Processo: 007549/2015-0) e da Fundação de Apoio à Pesquisa do Distrito Federal. O apoio de uma bolsa de pós-doutorado do programa Capes-Print, concedida no âmbito do Programa de Pós-Graduação em Linguística da Universidade Federal de Santa Catarina (UFSC), 
permitiv o aperfeiçoamento do texto. Os comentários dos revisores também contribuíram nesse sentido.

\section{REFERÊNCIAS}

BAKER, Mark. The macroparameter in a microparametric world. In: BIBERAUER, Theresa. The limits of syntactic variation. Amsterdam: John Benjamins, 2008. p. 351-74.

BERWICK, Robert; CHOMSKY, Noam. Why only us. Cambridge, MA: The MIT Press, 2016.

BIBERAUER, Theresa; ROBERTS, lan. Parameter Setting. In: LEDGEWAY, Adam; ROBERTS, lan. The Cambridge handbook of historical syntax. Cambridge: Cambridge University Press, 2017. p. 134-62.

BOECKX, Cedric. Approaching parameters from below. In: DI SCIULLO, Anna Maria; BOECKX, Cedric. The biolinguistic enterprise: New perspectives on the evolution and nature of the human language faculty. Oxford University Press, 2011. p. 205-221.

BORER, Hagit. Parametric syntax. Case studies in Semitic and Romance languages. Dordrecht: Foris, 1984

BORGES, Humberto. A sintaxe do sujeito na história do português brasileiro em Goiás: evidências oitocentistas de uma língua de sujeito nulo parcial. 2019. Tese (Doutorado em Linguística) - Departamento de Linguística, Português e Línguas Clássicas, Universidade de Brasília, Brasília, 2019. Disponível em:

https://repositorio.unb.br/bitstream/10482/35342/1/2019_HumbertoBorges.pdf. Acesso em: 22 ago. 2021.

CHOMSKY, N. Remarks on nominalization. In: JACOBS, R. A.; ROSENBAUM, P. S. Readings in English transformational grammar. Walthan, Mass: Braisdell, 1970. p. 184-221.

CHOMSKY, Noam. Lectures on government and binding theory. Dordrecht: Foris, 1981.

CHOMSKY, Noam. Knowledge of language: its nature, origin, and use. New York: Praeger, 1986.

CHOMSKY, Noam. Problems of projection extensions. In: DI DOMENICO, Elisa; HAMANN, Cornelia; MATTEINI, Simona. Structures, strategies and beyond. Studies in Honour of Adriana Belletti. Amsterdam: John Benjamins, 2015. p. 1-16.

CHOMSKY, Noam. Some concepts and consequences of the theory of government and binding. Cambridge, Mass.: The MIT Press, 1982.

CHOMSKY, Noam. The Minimalist Program. Cambridge, Mass.: MIT Press, 1995.

CHOMSKY, Noam. Three factors in language design. Linguistic Inquiry, v. 36, n. 1, p. 1-22, 2005.

FUB, Eric. Language change. In: ROBERTS, Ian. The Oxford handbook of Universal Grammar. Oxford University Press, 2016. p. 12-22.

GALVES, Charlotte; ANDRADE, Aroldo Leal de; FARIA, Pablo. Corpus histórico do português Tycho Brahe [Tycho Brahe Parsed Corpus of Historical Portuguese]. 2017. Disponível em: http://www.tycho.iel.unicamp.br/corpus/. Acesso em: 28 ago. 2021.

GALVES, Charlotte; CYRINO, Sônia; LOPES, Ruth.; SANDALO, Filomena; AVELAR, Juanito. Parameter theory and linguistic change. Oxford: Oxford University Press, 2012.

HOLMBERG, Anders. Is there a little pro? Evidence from Finnish. Linguistic Inquiry, v. 36, n. 4, p. 533-564, 2005.

HOLMBERG, Anders. Universal Grammar. In: LEDGEWAY, Adam; ROBERTS, lan. The Cambridge handbook of historical syntax. Cambridge: Cambridge University Press, 2017. p. 275-300.

HOLMBERG, Anders; ROBERTS, lan. The syntax-morphology relation. Lingua, v. 130, p. 111-131, 2013. 
HUANG, C.-T. James; ROBERTS, lan. Principles and Parameters of Universal Grammar. In: ROBERTS, lan. The Oxford handbook of Universal Grammar. Oxford University Press, 2016. p. 306-354.

KEENAN, Edward. Explaining the creation of reflexive pronouns in English. In: MINKOVA, Donka; STOCKWELL, Robert. Studies in the history of English: A millennial perspective. Berlin: Mouton de Gruyter, 2002. p. 325-355.

KROCH, Anthony. Modeling language change and language acquisition. Manuscrito. 2005.

$\mathrm{KROCH}$, Anthony. Reflexes of grammar in patterns of change. Language variation and change, v.1, n. 3, p. 199-244, 1989.

$\mathrm{KROCH}$, Anthony. Syntactic change. In: BALTIN, Mark; COLLINS, Chris. The handbook of contemporany syntactic theory. Oxford: Blackwell, 2001. p. 699-729.

KROCH, Anthony; TAYLOR, Ann; RINGE, Donald. The Middle English verb-second constraint: A case study in language contact and language change. In: HERRING, Susan; VAN REENEN, Pieter; SCHOESLER, Lene. Textual parameters in older language. Philadelphia: John Benjamins, 2000. p. 353-391.

LEDGEWAY, Adam; ROBERTS, lan. The Cambridge handbook of historical syntax. Cambridge: Cambridge University Press, 2017.

LIGHTFOOT, David. Acquisition and Learnability. In: LEDGEWAY, Adam; ROBERTS, lan. The Cambridge handbook of historical syntax. Cambridge: Cambridge University Press, 2017b. p. 381-400.

LIGHTFOOT, David. Imperfect transmission and discontinuity. In: LEDGEWAY, Adam; ROBERTS, lan. The Cambridge handbook of historical syntax. Cambridge: Cambridge University Press, 2017c. p. 515-533.

LIGHTFOOT, David. Transparency. In: LEDGEWAY, Adam; ROBERTS, lan. The Cambridge handbook of historical syntax. Cambridge: Cambridge University Press, 2017a. p. 322-337.

LIGHTFOOT, David. How new languages emerge. Cambridge: Cambridge University Press, 2006.

LIGHTFOOT, David. How to set parameters: Arguments from language change. Cambridge, MA: MIT Press, 1991.

LIGHTFOOT, David. Principles of diachronic syntax. Cambridge, UK: Cambridge University Press, 1979.

LIGHTFOOT, David. The development of language: Acquisition, change and evolution. Oxford: Blackwell, 1999.

LONGOBARDI, Giuseppe. Formal syntax, diachronic minimalism, and etymology: The history of French, Chez. Linguistic Inquiry, v. 32, n. 2, p. 275-302, 2001.

MADARIAGA, Nerea. Reanalysis. In: LEDGEWAY, Adam; ROBERTS, lan. The Cambridge handbook of historical syntax. Cambridge: Cambridge University Press, 2017. p. 70-91.

MARTINS, Ana Maria; NUNES, Jairo. Passives and se constructions. In: WETZELS, Leo, MENUZZI, Sérgio; COSTA, João. The handbook of Portuguese linguistics. Hoboken: Wiley-Blackwell, 2016. p. 318-337.

NARO, Anthony; SCHERRE, Maria Marta Pereira. Origens do português brasileiro. São Paulo: Parábola, 2007.

NEWMEYER, Frederick. Goals and methods of generative syntax. In: DEN DIKKEN, Marcel. The Cambridge handbook of generative syntax. Cambridge: Cambridge University Press, 2013. p. 61-92.

PIRES, Acrisio; LIGHTFOOT, David. Syntactic change. Oxford Bibliographies in Linguistics. 2013. Disponível em: https://www.oxfordbibliographies.com/view/document/obo-9780199772810/obo-9780199772810-0085.xml. Acesso em: 22 ago. 2021

ROBERTS, Ian. Diachronic syntax. Oxford: Oxford University Press, 2007.

ROBERTS, Ian; HOLMBERG, Anders. Introduction: parameters in minimalist theory. In: BIBERAUER, Theresa et al. Parametric variation: null subjects in minimalist theory. Cambridge: Cambridge University Press, 2010. p. 1-57.

ROBERTS, Ian; ROUSSOU, Anna. Syntactic change. A minimalist approach to grammaticalization. Cambridge: Cambridge University Press, 2003. 
ROEPER, Tom. Universal Bilingualism. Bilingualism: Language and Cognition, v. 2, n.3, p. 169-186, 1999.

WALKDEN, George. The Actuation Problem. In: LEDGEWAY, Adam; ROBERTS, Ian. The Cambridge handbook of historical syntax. Cambridge: Cambridge University Press, 2017. p. 403-424.

WEINREICH, Uriel; LABOV, William; HERZOG, Marvin. Empirical foundations for a theory of language change. In: LEHMANN, Winfred; MALKIEL, Yakov. Directions for historical linguistics. Austin and London: University of Texas Press, 1968. p. 95-189. 